\title{
Complement activation and anaphylactoid response to protamine in a child after cardiopulmonary bypass
}

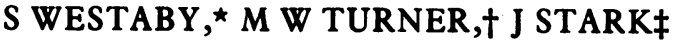 \\ From the ${ }^{\star}$ Department of Cardiac Surgery, Royal Postgraduate Medical School, Hammersmith Hospital; and the \\ $\dagger$ Department of Immunology and $¥$ Thoracic Unit, Hospital for Sick Children, London
}

SUMMARY A $2 \frac{1}{2}$ year old boy had a sudden, severe, and unexpected anaphylactoid reaction after an otherwise uncomplicated repair of a partial atrioventricular septal defect. The reaction, comprising haemorrhagic pulmonary oedema and peripheral circulatory collapse, followed neutralisation of heparin by protamine. Measurements of serum complement (C3 and $\mathrm{C4}$ ) concentrations suggested that a pronounced consumption of complement occurred during the adverse response.

Sudden severe anaphylactoid reactions after an otherwise uncomplicated cardiopulmonary bypass procedure have been reported previously and attributed to an abnormal response to protamine. ${ }^{2}$ The mechanism of this reaction, which comprises acute haemorrhagic pulmonary oedema with low left atrial pressure, peripheral circulatory collapse, and increased pulmonary vascular resistance, remains elusive. The reaction between heparin and protamine is, however, known to result in the consumption of complement in vitro, ${ }^{34}$ and recently one of us (SW) found complement activation with $\mathrm{C} 3 \mathrm{a}$ release after protamine infusion in patients undergoing coronary artery surgery (unpublished observations).

We recently encountered and successfully treated a severe anaphylactoid reaction after neutralisation of heparin with protamine in a child and obtained evidence of complement activation by the classical pathway.

\section{Case report}

A $2 \frac{1}{2}$ year old boy was admitted for repair of a partial atrioventricular septal defect. He had no previous history of allergy, blood transfusion, or drug sensitivity. Intracardiac repair was performed uneventfully, and cardiopulmonary bypass was discontinued without difficulty after 39 minutes. His haemodynamic status was stable with a systemic arterial pressure of $100 \mathrm{~mm}$ $\mathrm{Hg}$ and central venous pressure of $8 \mathrm{~mm} \mathrm{Hg}$. The venous cannulas were removed and protamine at a

Requests for reprints to Mr J Stark, Thoracic Unit, Hospital for Sick Children, Great Ormond Street, London WC1N 3JH. dose of $4.5 \mathrm{mg} / \mathrm{kg}$ given slowly over a period of 10 minutes. Five minutes after the infusion had been completed a sudden unexpected reaction occurred. The systemic blood pressure fell to below $30 \mathrm{~mm} \mathrm{Hg}$, although the mean left atrial pressure remained at 7 $\mathrm{mm} \mathrm{Hg}$. Pulmonary inflation pressure increased with decreasing pulmonary compliance, and there was a palpable rise in pulmonary arterial pressure. Haemorrhagic pulmonary oedema was noted by the anaesthetist when a large quantity of pink frothy secretion was aspirated from the endotracheal tube. Arterial saturation decreased and was followed by ventricular arrhythmia. The pleural cavities were opened to eliminate a local mechanical cause. The lungs were stiff, oedematous, and haemorrhagic.

Treatment was given immediately with intracardiac adrenaline and isoprenaline. A dopamine infusion was started $(10 \mathrm{mg} / \mathrm{kg} / \mathrm{min}$ ) and methyl prednisolone given at a dose of $30 \mathrm{mg} / \mathrm{kg}$. Sodium bicarbonate was required to correct metabolic acidosis, and plasma was infused to maintain right and left atrial pressures at satisfactory levels (left arterial pressure 7-10 mm $\mathrm{Hg}$ ). After a short period of cardiac massage the systemic pressure slowly rose. Subsequently, a period of systemic hypertension occurred, and frusemide $10 \mathrm{mg}$ $(1 \mathrm{mg} / \mathrm{kg}$ ) was given. During the period of resuscitation blood samples were taken to rule out a transfusion reaction to donor blood and for estimating concentrations of complement.

With this treatment the haemodynamics stabilised, and the chest was closed. A chest radiograph after return to the intensive care unit showed bilateral pulmonary oedema. The pulmonary oedema resolved completely during the next 24 hours, although the 


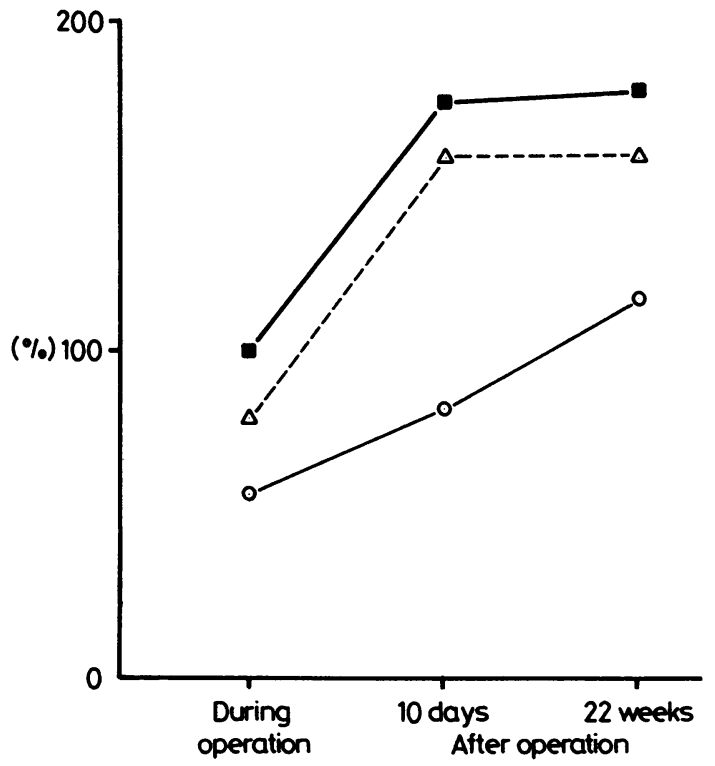

Figure Concentrations (percentage of standard) of the complement components $C 3(\square)$ and $C 4(\triangle)$ and total haemolytic complement $(O)$ (percentage of normal) in the patient at three sampling times.

boy required intermittent positive pressure ventilation for 48 hours. His subsequent postoperative course was uneventful, and he was discharged from hospital after 10 days.

Since a satisfactory preoperative blood sample was not available for baseline complement assays further samples were taken at 10 days and 22 weeks postoperatively. The Figure shows the $\mathrm{C} 3$ and $\mathrm{C} 4$ concentrations measured by single radial diffusion and the results of the total haemolytic complement assays. In contrast to the changes in the concentrations of the complement component the serum albumin concentrations during and after operation were exactly the same $(55 \mathrm{~g} / \mathrm{l})$. Studies of three similar patients undergoing surgery who received protamine without incident had essentially stable $\mathrm{C} 3$ and $\mathrm{C} 4$ concentrations before and after infusion (coefficient of variation $\leqslant 13 \%$ and $8 \%$ respectively).

\section{Discussion}

In this case study late postoperative $\mathrm{C} 3$ and $\mathrm{C} 4$ concentrations were almost identical to the 10 day samples and were assumed to reflect the patient's values for these acute phase proteins. In contrast, the sample taken during operation after the onset of pulmonary oedema and peripheral circulatory collapse showed a pronounced reduction in $\mathrm{C3}, \mathrm{C4}$, and total haemolytic complement suggesting that complement had been activated by the classical pathway.

Complement activation with release of the anaphylatoxins C3a and C5a is known to occur via the alternative pathway during cardiopulmonary bypass. ${ }^{5}$ $\mathrm{C} 4$ is not consumed in this process, and complement activation after protamine infusion occurs by a separate mechanism. This polycationic polypeptide produces cardiovascular side effects, characterised by Jastrebski et al in 1974, as a transient fall in systemic arterial pressure with a more prolonged rise in pulmonary arterial pressure. ${ }^{6}$ This is accompanied by a pronounced fall in arterial oxygen tension owing to a reduction in mixed venous oxygen tension which follows a fall in cardiac output. Left atrial pressure remains low implying an increase in pulmonary vascular resistance. ${ }^{7}$ The mechanism of these effects is still not clearly defined, but because of them protamine is infused slowly. The anaphylatoxins C3a and C5a have potent vasoactive properties. They increase vascular permeability, cause histamine release from mast cells, constrict smooth muscle, and may well account for the anaphylactoid reactions experienced by some patients. 8 Polymorphonuclear leucocytes and monocytes have membrane binding sites for C5a.9 C5a release results in altered mobility of these cells with sequestration in the pulmonary capillaries, a process associated with capillary endothelial damage and pulmonary oedema. ${ }^{1011}$

Previously, both anaphylactic ${ }^{12}$ and anaphylactoid responses to protamine infusion have been reported. Nordstrom et al described a case similar to our own in a 6 year old girl. ${ }^{1}$ Olinger et al described four patients with non-cardiogenic pulmonary oedema and peripheral vascular collapse from two separate cardiac units between 1969 and 1978. ${ }^{2}$ Of these, two patients died of low cardiac output and hypoxia while two survived after treatment with intravenous colloid infusion, methylprednisolone, catecholamines, and antihistamines. There were, however, notable differences in the character of these reactions between the patients, who cannot be assumed to be a homogeneous group. A variety of mechanisms may result in the syndrome of pulmonary hypertension, peripheral circulatory collapse, and increased capillary permeability. Among these are blood and drug reactions, endotoxic shock, allergic anaphylaxis, and nonimmune reactions mediated by complement and histamine. ${ }^{13}$ Our patient survived but required prompt and aggressive resuscitation directed towards a complement mediated anaphylactoid shock.

We thank Mr N Seymour for the assays of complement proteins. 
References

1 Nordstrom L, Fletcher R, Pavek K. Shock of anaphylactoid type induced by protamine: a continuous cardiorespiratory record. Acta Anaesthiol Scand 1978; 22: 195201.

2 Olinger GN, Becker RM, Bonchek LI. Noncardiogenic pulmonary edema and peripheral vascular collapse following cardiopulmonary bypass: rare protamine reaction? Ann Thorac Surg 1980; 29: 20-5.

3 Rent R, Ertel N, Eisentein R, et al. Complement activation by interaction of polyanions and polycations: I Heparin-protamine induced consumption of complement. J Immuinol 1975; 114: 120-4.

4 Siegel J, Rent R, Gewurz H. Interactions of C-reactive protein with the complement system: I. Protamineinduced consumption of complement in acute phase sera. f Exp Med 1974; 140: 631-47.

5 Chenoweth DE, Cooper SW, Hugli TE, et al. Complement activation during cardiopulmonary bypass: evidence for generation of $\mathrm{C} 3 \mathrm{a}$ and $\mathrm{C5a}$ anaphylatoxins. $N$ Engl f Med 1981; 304: 497-503.

6 Jastrebski J, Sykes MK, Woods DG. Cardiorespiratory effects of protamine after cardiopulmonary bypass in man. Thorax 1974; 29: 534-8.
7 Shapira N, Schaff HV, Piehler JM, et al. Cardiovascular effects of protamine sulfate in man. $\mathcal{F}$ Thorac Cardiovasc Surg 1982; 84: 505-14.

8 Hugli TE. Chemical aspects of the serum anaphylatoxins. In: Reisfeld RA, Mardy JW, eds. Contemporary topics of molecular immunology. Vol 7. New York: Plenum Press, 1978: 181-214.

9 Chenoweth DE, Hugli TE. Binding, internalization and degradation of C5a by neutrophils [Abstract]. Fed Proc 1980; 39: 1049.

10 Hammerschmidt DE, Stroncek DF, Bowers TK, et al. Complement activation and neutropenia occurring during cardiopulmonary bypass. $f$ Thorac Cardiovasc Surg 1981; 81: 370-7.

11 Hohn DC, Meyers AJ, Gherini ST, et al. Production of acute pulmonary injury by leukocytes and activated complement. Surgery 1980; 88: 48-58.

12 Lakin JD, Blocker TJ, Strong DM, Yocum MW. Anaphylaxis to protamine sulphate mediated by a complement dependent IgG antibody. $\mathcal{F}$ Allengy Clin Immunol 1978; 61: 102-7.

13 Pavek K. Anaphylactic shock in the monkey, its hemodynamics and mediators. Acta Anaesthesiol Scand 1977; 21: 293-307.

\section{Notices}

\section{European coronary angioplasty workshop}

A meeting on coronary angioplasty is to be held from 10 to 12 July 1985 at The London Hospital. Further information may be obtained from: PTCA Workshop, c/o Cardiac Department, The London Hospital, Whitechapel, London E1 1BB.

\section{Geriatric cardiology}

The 2nd International Conference on Physical Activity, Aging, and Sports will be held at West Point, New York, from 8 to 12 July 1985. Further information may be obtained from PAAS-'85, Center for the Study of Aging, 706 Madison Avenue, Albany, New York 12208, USA.

\section{British Cardiac Society}

The Autumn Meeting will be held at the Wembley Conference Centre, London, on 26 to 28 November 1985 , and the closing date for receipt of abstracts will be 1 August 1985.

The Annual General Meeting for 1986 will take place in York on 2 and 3 April 1986, and the closing date for receipt of abstracts will be 2 January 1986 . 